\title{
Central peptidergic control of gastric acid secretion
}

Recent advances in the neurosciences have produced new insights into gut physiology and the nature of brain-gut interaction. In particular, studies of central effects of peptides on gastric secretion have contributed greatly to our understanding of the mechanisms by which the brain regulates gut function. As well as demonstrating specific roles for many peptides in the brain-gut axis, recent studies have also disclosed some important general principles that are worthy of consideration. These developments have yielded valuable insights into aspects of gut physiology, which are of relevance to clinical gastroenterologists.

The connection between emotional perturbation and disorders of the stomach must have been apparent even to the most primitive of human cultures. Early clinical and animal experimental observations provided evidence of a functional link between the brain and the gut. The expansion in biochemical and immunohistochemical technology that occurred during the 1960 s led to the identification of a large number of peptide neurotransmitters in the brain. The demonstration that substance $P$, vasoactive intestinal peptide, and somatostatin were present in both the brain and the gut raised questions about the nature of brain-gut interaction. ${ }^{1-3}$ The subsequent identification by Dockray in 1976 of high concentrations of cholecystokinin (CCK) in the brain of rats, pigs, and dogs was of enormous importance. ${ }^{4}$ Here was one of the preeminent gut peptides, with a well established hormonal action, unexpectedly identified in high concentrations in the brain where it functioned as a neurotransmitter. In many instances peptide and non-peptide neurotransmitters are colocalised in the same neural terminals where they may interact functionally. Non-peptide neurotransmitters undoubtedly play a part in central regulation of gastric secretion. However, their effects are beyond the scope of this article.

The demonstration of dual localisation of some regulatory peptides in the brain and the gut stimulated a number of researchers to examine the central effects of these peptides on gut function, in particular gastric acid secretion. Indeed, many neuropeptides were shown to have powerful effects on gastric acid secretion (see Table I). The preponderance of inhibitory over stimulatory peptides is not surprising as the efficiency of any secretory system depends largely on its inhibitory mechanisms. In a few instances physiological roles for these peptides have been established, usually by the use of specific antagonists. In

TABLE I Peptides that affect gastric acid secretion after central injection (refs 5-16)

\begin{tabular}{ll}
\hline Inhibitors & Stimulators \\
\hline CRF & TRH \\
$\beta$ endorphin & Somatostatin \\
Bombesin & NPY \\
Neurotensin & Galanin \\
Calcitonin & PYY \\
CGRP & \\
Interleukin 1 & \\
\hline
\end{tabular}

the absence of specific antagonists, the physiological significance of pharmacological studies with brain-gut peptides is harder to confirm but may be inferred by the accumulation of sufficient circumstantial evidence.

\section{Thyrotropin releasing hormone}

Thyrotropin releasing hormone (TRH) was the first brain peptide shown to affect gut function after central administration. ${ }^{17}$ When TRH was first identified in 1970, it was assumed that it served a specific function in the hypothalamo-hypophyseal axis. Immunohistochemical localisation studies showed, however, that TRH was also found in other extra-hypothalamic sites in areas known to be important for integration of visceral function, with high concentrations in the vagal nuclei in the brainstem. In 1977, Smith and colleagues reported that intracerebroventricular injection of TRH caused an increase in colonic motor activity in rabbits. ${ }^{17}$ This was the first report of a central effect of a neuropeptide on gut function. Taché subsequently reported that intracisternal TRH has a potent stimulatory effect on gastric acid secretion in rats that was completely independent of its hypophysiotropic action. ${ }^{18}$ Central administration of TRH also increases gastric emptying and gastric mucosal blood flow in rats. ${ }^{19} \mathrm{~A}$ considerable amount of convergent evidence, including localisation, immunoneutralisation, and analogue studies, supports the hypothesis that TRH plays a physiological part in central regulation of gastric acid secretion. The highest concentrations of TRH receptors are found in the dorsal vagal nuclei, ${ }^{20}$ the final common pathway for vagal outflow from the brain to the stomach. Many different higher centres exert an influence on gastric acid secretion and it has been proposed that these higher signals converge through this TRH mediated pathway.

\section{Bombesin}

Evidence is accumulating that bombesin also has a significant role in central control of acid secretion. ${ }^{7}$ Central injection of bombesin potently inhibits acid secreted in response to a variety of central and peripheral stimulants, the opposite of its well established peripheral stimulatory effect on acid secretion. The central inhibitory action of bombesin is not affected by vagotomy, but is abolished by cervical transection and $\alpha_{2}$ adrenergic blockade, showing that its central effect is mediated through the sympathetic nervous system. ${ }^{21}$ Indeed, many of the peptide effects described have been shown to be mediated by non-vagal pathways. As yet, no centrally administered peptide has been shown to affect gastric secretion by altering gastrin release.

\section{Corticotropin releasing factor}

The physiological response to stress involves a complex array of adjustments in cardiorespiratory, gastrointestinal, 
and endocrine function that equips the subject to deal with stress. Although the peripheral manifestations of the stress response are well described, candidate central mediators have only recently been identified with corticotropin releasing factor (CRF) emerging as an important mediator of the stress response. Although first identified in the hypothalamo-hypophyeal axis, CRF was soon shown to be also present in extra-hypothalamic sites in the CNS. Studies of exogenous administration of CRF into the brain show that it elicits the full spectrum of cardiovascular, metabolic, endocrine, gastrointestinal, and behavioural effects associated with stress. ${ }^{22}$

The potent inhibitory effect of intracerebroventricular CRF on gastric acid secretion was first described by Taché. ${ }^{5}$ This inhibitory experimental action is compatible with the finding that stress ulceration in animal models and in stressed patients is associated with decreased rather than increased acid secretion. CRF also causes retardation of gastric emptying, and small bowel transit, and a pronounced increase in colonic motility. ${ }^{22}$ These effects are produced by interaction with a number of other neurotransmitters including opiates and are probably, at least in part, vagally transmitted. ${ }^{22}$ Studies performed with a-helical 9-41 CRF, a specific CRF antagonist, confirm that these are physiological effects of CRF.

\section{Opioids}

A physiological role for opioids in modulating the gastric response to stress has been demonstrated by studies using opioid antagonists. Central administration of opioids inhibits acid secretion by a vagal mechanism. These agents also inhibit the formation of stress induced gastric ulcers suggesting that opioids protect against stress induced alteractions in gastric function. ${ }^{6}$ Further studies with specific opioid receptor subtype antagonists should clarify their role in modulation of stress effects on gastric secretion.

\section{Neurotensin}

Neurotensin has also been implicated as a mediator of the stress response. Centrally administered neurotensin decreases gastric acid secretion and has a protective effect on stress induced gastropathy in a number of animal models. ${ }^{8}$ The central site of this effect is probably in the limbic system, and entails interaction with adrenergic and dopaminergic pathways. ${ }^{823}$ The peripheral effect is produced by changes in peripheral prostaglandin production and gastric mucosal blood flow.

\section{Calcitonin and calcitonin gene related peptide}

Calcitonin and calcitonin gene related peptide (CGRP) may also be involved in gastric mucosal protection, ${ }^{9} 1024$ although they seem to act through different mechanisms. Central calcitonin inhibits the development of stress induced ulcers. ${ }^{9}$ Most evidence points to a peripheral role for CGRP in gastric cytoprotection, however, some studies suggest that it may also have a central effect, which seems to be produced by modulation of central parasympathetic outflow resulting in increased mucosal blood flow. Further studies are required to unravel the functional relations between the different peptides that play a central part in protection against stress.

\section{Interleukin 1}

Several studies have demonstrated interaction between gut peptides and mediators of immune responsiveness within the gastrointestinal tract. A recent report showed that intracerebroventricular interleukin 1 inhibits acid secretion in rats, providing evidence that immunological mediators may also affect gut function through central mechanisms. ${ }^{11}$ Interleukin 1 also inhibits gastric emptying and small intestinal motility, and stimulates colonic motility through prostaglandin and CRF mediated pathways. While work in this area is still at an embryonic stage, none the less these findings suggest possible important mechanisms by which the systemic response to inflammation and stress may be coordinated.

\section{Neuropeptide $\mathbf{Y}$}

Neuropeptide Y (NPY), a member of the pancreatic polypeptide family, is the most potent known stimulant of feeding and is found in higher concentrations within the CNS than any other neuropeptide. Its potency as an orexigenic agent and the preservation of its effects across a range of species suggest that NPY plays an important part in the initiation of feeding behaviour.

Recent observations of the effect of central administration of NPY in dogs show that NPY cannot only initiate feeding but can also trigger a range of gut secretory and motor effects, which normally occur at the onset of feeding. ${ }^{14}$ Central administration of NPY increased not only gastric acid (by a vagal pathway), but also pancreatic and biliary secretion and converted the fasting pattern of cyclical myoelectric activity in the stomach and small intestine to the pattern seen after feeding. ${ }^{25}{ }^{26}$ Administration of an NPY antagonist to sham feeding dogs with oesophageal fistula prevented the cephalic phase gastric acid response, proving that the effect of NPY on gastric acid secretion is a physiological one. ${ }^{27}$

Galanin, another initiator of feeding behaviour, has a similar though less potent central effect on acid secretion. ${ }^{15}$

These studies suggest that NPY as well as being involved in the initiation of feeding might also be responsible for triggering the full range of secretory and motor responses that prepare the gut for ingested food. The single peptide may be responsible for coordinating a broad range of functions that serve a common purpose. The concept that the same peptide that is responsible for activating feeding also triggers an appropriate preparatory secretory response is attractive because it suggests the sort of simple economy that characterises many biological systems. CRF, in similar fashion, seems to be responsible for coordinating an integrated response to stress. These findings suggest that peptide neurotransmitters play important integrative parts within the CNS, providing templates for coordinated homeostatic and visceral responses to certain specific situations.

\section{Opposing central and peripheral actions of brain-gut peptides}

One the the most intriguing findings to emerge from studies of central administration of peptides on gut function has been that some peptides have opposite central and peripheral effects on gastric secretion (Table II). This

TABLE II Peptides with opposing central and peripheral effects on gastric acid secretion (refs $7,13,14,15$ )

\begin{tabular}{lll}
\hline & Effect on acid secretion & \\
\cline { 2 - 3 } & Intracerebroventricular & Intravenous \\
\hline Bombesin & $\downarrow$ & $\vdots$ \\
Somatostatin & $\vdots$ & $\vdots$ \\
Galanin & $\vdots$ & $\vdots$
\end{tabular}


phenomenon has been best described for peptides that affect gastric secretion however it has also been noted that CCK and opiates have opposing central and peripheral effects on gastric emptying and pain modulation respectively, suggesting that it may be a more generalised occurrence than is currently recognised. ${ }^{28} 29$ This phenomenon shows the importance of the compartmentalisation provided by the blood-brain barrier. In general, the bloodbrain barrier limits diffusion of peptides from the peripheral circulation to the brain interstitial fluid and vice versa. However, in a number of areas, collectively known as the circumventricular organs, the blood-brain barrier is deficient permitting peripheral circulating peptides access to the central nervous system. Receptor binding studies have demonstrated receptors for many of the gut peptides in these areas, providing an anatomical substrate for feedback effects of circulating gut peptides on centrally controlled gut functions. ${ }^{30}$ Binding of peptides that circulate peripherally to receptors in the circumventricular organs is probably an important pathway for feedback control of gut function through central pathways. ${ }^{31}$

\section{Conclusion}

It is worth recalling that, apart from the central nervous system, the gastrointestinal tract has the highest concentration of neural elements of any organ in the body. An understanding of the interaction between the brain and the gut is becoming increasingly important for anyone interested in gastrointestinal physiology and pathophysiology. Although still in its infancy, the study of brain-gut interaction has yielded important advances in the understanding of normal gut function and in explaining a number of gastrointestinal disorders. Elucidation of the central pathway through which the brain regulates gastric function may lead to the development of new strategies for pharmacological manipulation of acid secretion and gastric motility.

Department of Surgery, St Vincent's Hospital,

JUSTIN G GEOGHEGAN Elm Park, Dublin 4, Ireland

Department of Surgery, Duke University Medical Center

ORE N PAPPAS Durham, NC 27710, USA

Correspondence to: Mr J G Geoghegan

1 Chang MN, Leeman SE. Isolation of a sialagogic peptide from bovine hypothalamic tissue and its characterization as substance P. 7 Biol Chem 1970; 245: 4784

2 Krulich L, Dhavival APS, McCann SM. Stimulatory and inhibitory effects of purified hypothalamic extracts in growth hormone release from rat pituitary in vitro. Endocrinology 1968; 83: 783-90.

3 Fuxe K, Hokfelt T, Said SI, Mutt V. Vasoactive intestinal polypeptide and the nervous system: immunohistochemical evidence for localization in central and peripheral neurons, particularly intracortical neurons of the cerebral cortex. Neurosci Lett 1977; 5: 241-6.
4 Dockray GJ. Immunochemical evidence of cholecystokinin-like peptides in brain. Nature 1976; 264: 568-70.

5 Lenz HJ, Raedler A, Greten H, Vale WW, Rivier J. Stress induced gastrointestinal secretory and motor responses are mediated by endogenous corticotropin-releasing factor. Gastroenterology 1988; 95: 1510-7.

6 Scoto GM, Parenti C. Prevention of stress-induced gastric ulcers by muand delta-opoid agonists in the rat. F Physiol (Paris) 1993; 87: 385-8.

7 Pappas TN, Hamel D, Debas HT, Walsh JH, Taché Y. Cerebroventricular bombesin inhibits gastric acid secretion in dogs. Gastroenterology 1985; 89: 43-8

8 Zhang L, Xing LP, Demers L, Washington J, Kauffman GL Jr. Central neurotensin inhibits gastric acid secretion: an adrenergic mechanism in rats. Gastroenterology 1989; 97: 1130-4.

9 Morley JE, Levine AS, Silvis SE. Intraventricular calcitonin inhibits gastric acid secretion. Science 1981; 214: 671-3.

10 Raché Y. Inhibition of gastric acid secretion and ulcers by calcitonin generelated peptide. Ann NY Acad Sci 1992; 657: 240-7.

11 Taché Y, Saperas E. Potent inhibition of gastric acid secretion and ulcer formation by centrally and peripherally administered interleukin-1. Ann formation by centrally and periphe

12 Taché $\mathrm{Y}$, Vale W, Brown $\mathrm{M}$. Thyrotropin-releasing hormone-CNS action to stimulate gastric acid secretion. Nature $1980 ; 287$ : 149-51

13 Pappas TN, Taché Y, Debas HT. Cerebroventricular somatostatin stimulates gastric acid secretion in the dog. In: Lewin MJ, Bonfils S, eds Regulatory peptides in digestive, nervous, and endocrine systems. INSERM Symposium No 25. Amsterdam: Elsevier, 1987: 323-7.

14 Geoghegan JG, Lawson DC, Cheng CA, Opara E, Taylor IL, Pappas TN. Intracerebroventricular neuropeptide $\mathrm{Y}$ increases gastric and pancreatic secretion in the dog. Gatroenterology 1993; 105: 1069-77.

15 Geoghegan JG, Lawson DC, Pappas TN. Neuropeptide Y and galanin opposite central and peripheral effects on gastric acid secretion. $\mathcal{F}$ Neurosci opposite centra 190 : 189.

16 Yang H, Taché Y. PYY in brain stem nuclei induces vagal stimulation of gastric acid secretion in rats. Am F Physiol 1995; 268: G943-8.

17 Smith JR, La Hann TR, Chesnut RM, Carino MA, Horita A. Thyrotropinreleasing hormone: stimulation of colonic activity following intracerebroventricular administration. Science $1977 ; 196: 660-2$.

18 Taché Y, Lesiege D, Vale W, Collu R. Gastric hypersecretion by intracisternal TRH: dissociation from hypophysiotropic activity and role of central catecholamine. Eur f Pharmacol 1985; 107: 149-55.

19 Taché Y, Stephens RL, Ishikawa T. Central nervous system action of TRH to influence gastrointestinal function and ulceration. Ann NY Acad Sci 1989; 553: 269-85.

20 Palkovits M, Mezey E, Eskay RL, Brownstein MJ. Innervation of the nucleus of the solitary tract and dorsal vagal nucleus by thyrotropinreleasing hormone-containing raphe neurons. Brain Res 1986; 373. $246-51$.

21 Taché Y, Lesiege D, Goto Y. Neural pathways involved in intracisternal bombesin-induced inhibition of gastric secrection in rats. Dig Dis Sci 1986; 31: 412-7.

22 Taché Y, Goto Y, Gunion MW, Greten H. Central nervous system action of corticotropin-releasing factor on gastrointestinal transit in the rat. Gastroenterology 1988; 94: 598-602.

23 Henke PG, Sullivan RM, Ray A. Interactions of thyrotropin-releasing hormone (TRH) with neurotensin and dopamine in the central nucleus of the amygdala during stress ulcer formation in rats. Neurosci Lett 1988 91: $95-100$.

24 Gray JL, Bunnett NW, Orloff SL, Mulvihill SJ, Debas HT. A role of calcitonin gene-related peptide in protection against gastric ulceration. Ann Surg 1994; 219: 58-64.

25 Farouk M, Geoghegan JG, Pruthi RS, Thomson HJ, Pappas TN, Meyers WC. Intracerebroventricular neuropeptide $\mathrm{Y}$ stimulates bile secretion by a vagal mechanism. Gut 1992; 33: 1562-5.

26 Thompson HJ, Geoghegan JG, Farouk M, et al. Exogenous neuropeptide $\mathrm{Y}$ blocks myoelectric activity in the upper gastrointestinal tract. Brain neuropeptide $\mathrm{Y}$ converts a fasting pattern of myoelectric activity to a fed pattern. Scand $\mathcal{F}$ Gastroenterol 1993; 28: 469-74

27 Lee M, Lawson DC, Pappas TN. Neuropeptide Y functions as a physiologic regulator of cephalic phase acid secretion. Regul Pept 1994; 52: 227-34

28 Pappas TN, Taché Y, Debas HT. Opposing central and peripheral actions of brain-gut peptides: a basis for regulation of gastric function. Surger 1985; 98: 183-9.

29 Bechara A, van der Kooy D. Opposing motivational effects of endogenous opiates in brain and periphery. Nature $1985 ; 314$ : 533-4.

30 Whitcomb D, Vigna S, Taylor IL. Characterization of saturable binding sites for circulating pancreatic polypeptide in rat brain. Am f Physiol 1990; 259: G687-91.

31 McTigue DM, Rogers RC. Pancreatic polypeptide stimulates gastric acid secretion through a vagal mechanism in rats. Am f Physiol 1995; 269 R983-7 